\title{
Meio, mediação, agência: a descoberta dos objetos em Walter Benjamin e Bruno Latour
}

\section{Erick Felinto}

\section{Resumo}

Não obstante a originalidade das proposições de Bruno Latour, seria equivocado dizer que sua obra foi gestada em um vácuo teórico. As influências de pensadores como Étienne Souriau, Gilbert Simondon e Gabriel Tarde, por exemplo, foram dissecadas cuidadosamente pela crítica. 0 objetivo deste trabalho é esboçar convergências importantes entre o pensamento de Latour e certas ideias de Walter Benjamin, expressas de forma mais incisiva em alguns textos de juventude. Através dessa aproximação, já ensaiada anteriormente por alguns autores, pretende-se dar início a uma exploração filosófica dos conceitos de agência, meio e mediação - fundamentais para a reflexão comunicacional, especialmente no contexto contemporâneo.

\section{Palavra-Chave}

Bruno Latour. Walter Benjamin. Agência. Mediação. Comunicação.
Erick Felinto I erickfelinto@gmail.com Doutor em Literatura Comparada pela Universidade do Estado do Rio de Janeiro (UERJ). Professor Associado da Faculdade de Comunicação Social da Universidade do Estado do Rio de Janeiro (UERJ).

\section{Bruno Latour e sua angústia da influência}

Poucos textos conheceram, entre os estudiosos da comunicação, fortuna mais expressiva que o clássico ensaio de Walter Benjamin A obra de arte na época de sua reprodutibilidade técnica. A bem da verdade, poder-se-ia dizer, com Detlev Schöttker (2007, p. 103), que esse pequeno artigo de aproximadamente 40 páginas, conquistou, no decorrer de sua relativamente breve pós-história, o status internacional de uma obra do século. Dada sua relativa clareza em relação a muitos outros escritos de Benjamin e 0 fato de constituir uma competente e sintética recensão das ideias do autor sobre arte, meios tecnológicos de comunicação e teoria cultural, não surpreende 0 fascínio que 0 texto ainda hoje exerce - especialmente sobre os estudiosos da comunicação.

Todavia, o excessivo burburinho em torno desse trabalho, reelaborado e modificado diversas vezes, constitui possivelmente uma injustiça para com a vasta obra de um autor tão complexo 
e multifacetado como Benjamin. Essa injustiça pode manifestar-se em diversas formas, seja por meio de um exagerado apego a certas questões pontuais (como o problema da "aura") em detrimento uma visão de conjunto, seja por meio de alguns reducionismos simplificadores, como fazem, por exemplo, Bruno Latour e Antoine Hennion em seu artigo provocativamente intitulado How to make mistakes on so many things at once - and become famous for it. 0 artigo, reproduzido na coletânea organizada por Michael Marrinan e Hans Ulrich Gumbrecht (2003) para reavaliar criticamente 0 ensaio benjaminiano no contexto da cultura digital, adota uma postura de condenação virulenta, anunciada já na ironia do próprio título. Sem entrar no mérito das reprimendas em si, algumas delas bastante interessantes e convincentes, chama atenção o tom de agressividade com que os autores atacam o pensamento de Benjamin. Este teria cometido equívocos em todos os domínios por ele abordados (arte, cultura, arquitetura, economia, técnica etc.); suas proposições se articulariam em torno de uma "dicotomia repetitiva" que funcionaria mais como estratégia para evitar críticas que como real instrumento epistemológico; seu raciocínio resumir-se-ia, no fim das contas, a uma "complacente denúncia da modernidade" (BENJAMIN, 2003, p. 92, 97). ${ }^{1}$
Naturalmente, antes de tudo, deve-se ter em mente que 0 estilo bombástico e 0 gosto pela polêmica constituem estratégias corriqueiras no repertório discursivo de um pensador como Latour, conhecido por produzir enfáticas afirmações como: "sempre achei espantoso que as pessoas pudessem levar a sério a filosofia da tecnologia de Heidegger" (LATOUR, ERDÉLY; HARMAN, 2011, p. 5). ${ }^{2}$ Todavia, surpreende tamanha virulência dirigida a um autor como Benjamin, capaz de angariar admiração em círculos acadêmicos tão diferentes como os da crítica literária, da antropologia ou dos estudos de comunicação. Se é verdade que vale a pena desconfiar de toda e qualquer unanimidade, há ocasiões em que é útil também desconfiar da desconfiança. Afinal - e não obstante o possível acerto de algumas de suas críticas -, o panfleto de Latour e Hennion ocupa uma posição bastante minoritária na história das interpretações do texto benjaminiano. Importa, ainda, assinalar como o ensaio de Benjamin vem recebendo renovada atenção por meio de sua releitura no contexto da cultura digital. Nesse contexto, Mark Hansen (2004, p. 1) é certamente um dos autores que percebeu com maior clareza a real contribuição benjaminiana:

Em certo sentido, já superamos o tema da aura, mas ainda não superamos a questão do meio; ou, de qualquer modo, gostaríamos de pensar que não o fizemos. De fato, as reflexões de Benjamin sobre o meio (medium) nunca

Uma afirmativa, de fato, que muitos leitores de Benjamin, nos mais diversos espectros ideológicos, rechaçariam.

A sentença refere-se, mais especificamente, ao clássico ensaio de Heidegger Die Frage nach der Technik. Curiosamente, porém, vários autores, como Harman (2009) e Latour, Harman e Erdély (2011), têm buscando insistentemente destacar as várias e importantes conexões entre a filosofia de Heidegger e o pensamento de Latour. 
foram tão urgentes como agora, no contexto de afirmativas como a de que, com a digitalização, os meios se tornaram inteiramente e bidireccionalmente intercambiáveis.

0 presente artigo se estrutura em torno de dois objetivos. Por um lado, quero sugerir que a popularidade (por vezes efetivamente acrítica) do ensaio sobre a obra de arte contribuiu para obnubilar outros trabalhos de Benjamin que não receberam ainda a merecida atenção - ao menos entre os pesquisadores de comunicação. Isso sem falar numa certa "pasteurização" de conceitos e ideias que não faz jus ao pensamento do filósofo, como, por exemplo, a tese da ruptura entre o Benjamin "místico" dos primeiros trabalhos e o marxista comprometido da obra "madura". Por outro lado, arrisco buscar uma explicação para as agressivas formulações de Latour e Hennion paradoxalmente no que me parece ser uma extrema proximidade entre certas ideias benjaminianas e as premissas da teoria ator-rede. Ou seja, na crítica demolidora, trata-se de demarcar a resoluta singularidade de um pensamento através do distanciamento com outro domínio conceitual que, analisado cuidadosamente, revela essencialmente as mesmas linhas de força e premissas epistemológicas. Seria divertido - e possivelmente não inteiramente despropositado - imaginar um Latour vítima daquele mecanismo do fazer literário que o crítico Harold Bloom (1997) descreveu como "angústia da influência": para marcar sua identidade singular em relação aos mestres que o precederam, o jovem "efebo" rompe com esses precursores, atacando- os violentamente, por meio de sua "desleitura" (misreading). Naturalmente, ele absorve a herança de seus pais simbólicos (por exemplo, Heidegger ou Benjamin), mas busca a todo custo afastar-se deles, de modo a produzir uma obra efetivamente "original".

Outrossim, como Latour e Hennion (2003, p. 92) deixam claro no final de seu artigo, Benjamin seria para eles apenas um caso representativo de um universo mais amplo: "os teóricos da modernidade alemães", que viam as massas modernas como inteiramente determinadas pelos aparatos técnicos. Mas é aqui, precisamente, que os autores também correm o risco de incorrer num equívoco perigoso: o de assimilar Benjamin, sem reservas, a certa tradição majoritária do pensamento alemão sobre a mídia; uma tradição marcada pelo acento apocalíptico e pela recusa radical das inovações tecnológicas (em especial no âmbito da Escola de Frankfurt). No que diz respeito especificamente ao ensaio sobre a obra de arte, vale assinalar as nítidas discordâncias manifestadas pela Escola. Em sua cuidadosa reconstituição da história de elaboração do texto benjaminiano, Schöttker mostra nitidamente como Adorno e Horkheimer colocaram diversos empecilhos à publicação do ensaio de Benjamin no Zeitschrift für Sozialforschung. Numa carta de 18 de março de 1919 endereçada a Benjamin, assim Adorno (1919 apud SCHÖTTKER, 2007, p. 127) expressa suas reservas: "você subestima a tecnicidade da arte autônoma e superestima aquela da arte submissa (abhängigen). Essa seria 
talvez, em linhas gerais, minha objeção principal".

Mas, como mostra Schöttker, foram muitas e variadas as resistências de Adorno e Horckheimer ao trabalho de Benjamin. Desse modo, mesmo que considerássemos Benjamin como um legítimo frankfurtiano, seu ensaio sobre a obra de arte certamente parecia pouco apropriado aos princípios do Instituto. ${ }^{3}$

No que se segue, considerando a indicação de Hansen (2004) acima mencionada, pretendo explorar o potencial das reflexões de Benjamin sobre meio, mediação e medialidade para a teoria da mídia na contemporaneidade. Essas reflexões encontram sua expressão mais interessante, porém, em dois ensaios de Benjamin que têm como tema a questão da linguagem: Sobre a Linguagem em Geral e sobre a Linguagem do Homem (1916) e A Tarefa da Tradutor (1921) - textos que, aliás, têm sido comumente lidos em molduras interpretativas comuns.

Nessa investigação, deverão ficar claros os interessantes pontos de contato que unem 0 pensamento de Benjamin aos princípios da teoria ator-rede e, consequentemente, às propostas de Latour. Essas reflexões permitem, por um lado, confirmar a surpreendente atualidade do pensamento benjaminiano. Por outro, colaboram para o projeto (cada vez mais necessário) de aprofundar as discussões sobre 0 conceito de meio, especialmente no âmbito dos debates sobre teoria da comunicação no Brasil, nos quais ele é frequentemente utilizado como baliza para recortar as "legítimas" fronteiras epistemológicas da disciplina. E isso não obstante o fato de "meio" ser insistentemente tratado como uma noção que carece de maiores explicitações. É importante assinalar, logo de início, que a conexão BenjaminLatour não constitui um gesto de ousadia teórica inaugural do autor deste texto, mas já foi, como se verá, assinalada algumas vezes em estudos recentes (KIMMICH, 2011; BUSCH, 2006).

\section{Meio, Comunicação, Medialidade:}

\section{Devolvendo Opacidade} a Conceitos Transparentes

No intrigante Pequena Metafísica da Medialidade, Sybille Krämer (2008) inicia sua discussão de Walter Benjamin precisamente com uma referência ao clássico ensaio sobre a obra de arte. Reconhecendo o grande mérito do autor nesse texto - pioneiro, na descoberta das mútuas relações de condicionamento entre técnica e arte, tecnologia e percepção, meios e sensorialidade -, Krämer surpreende, contudo, por passar logo em seguida a uma análise da hermética reflexão benjaminiana sobre a linguagem. De fato, 0 tremendo êxito de $A$ obra de arte na época de sua reprodutibilidade técnica ameaça sempre obscurecer a importância de trabalhos de juventude como o ensaio sobra a linguagem 
citado no parágrafo anterior. Krämer (2008) assinala como os debates contemporâneos sobre os meios negligenciaram a interessante abordagem benjaminiana dos conceitos de "comunicação" (Mitteilung), "meio" (Medium) e "medial" (Mediales). Claro, essa negligência se explica, ao menos em parte, em função do caráter eminentemente esotérico do ensaio. Como anteriormente já advertira Menninghaus (1995), Krämer (2008) lembra também que Benjamin não pretendia publicar 0 trabalho, mas apenas oferece-lo à leitura de um pequeno círculo de amigos. ${ }^{4}$ Além disso, vale ressalvar que, como sucede em $A$ tarefa do tradutor, a reflexão filosófica se encontra aqui mesclada a uma série de referências misteriosas à tradição mística judaica (a Cabala) - o que, naturalmente, acabou por dar margem a uma série de preconceitos e equívocos em relação ao escrito.

Menos que reconstituir a totalidade das ideias benjaminianas sobre a linguagem, o objetivo de Krämer (2008, p. 42) é buscar "pelos rastros de um conceito de meios (Medienkonzept) no jovem Benjamin; conceito que é determinado por uma divergência entre meio (Medium) e instrumento técnico". Que a comunicação necessite de um meio para funcionar e que a linguagem constitua o meio da comunicação (Medium der Mitteilung) parecerá tão óbvio a ponto de não exigir qualquer discussão posterior. Todavia, essas noções adquirem no texto de Benjamin um sentido que vai contra nosso entendimento tradicional e familiar de meio, comunicação e linguagem. Tal sentido conduzirá, no fim das contas, a uma afirmação da ideia da tradução ou traduzibilidade como tarefa fundamental do medial. A problematização desses conceitos tem início com a estranha afirmativa de que é possível falar em uma linguagem da justiça, da arte ou da religião - sem que com isso se entenda 0 discurso dos especialistas sobre esses domínios (BENJAMIN, 1991a, p. 140). Não se trata de verbalizar conteúdos ou noções desses campos (por exemplo, o princípio de "direito autoral" no campo da justiça), mas sim que há algo de essencial na justiça, na arte ou na religião que se manifesta como linguagem. Ou seja, a comunicação de um atributo não é privilégio exclusivo das esferas culturais tradicionais do sentido (humano), "mas também das coisas de natureza viva ou morta. Existem para Benjamin, portanto, 'línguas da coisas"” (KRÄMER, 2008, p. 44).

É precisamente nessa ideia central, expressa já no curioso título - afinal, o que quer dizer "linguagem em geral" (Sprache überhaupt) se só conhecemos a linguagem dos homens? -, que repousa a mais interessante contribuição de Benjamin a um debate extremamente contemporâneo. Nessa concepção inovadora, não são somente os seres humanos que se expressam, senão também as coisas. De fato, como afirma Benjamin, não existe nada que não participe, de algum modo, do ser da linguagem. Mas trata-se, obviamente, de um outro 
entendimento de linguagem, por meio do qual o pensador se despede de pelo menos três atributos comumente adstritos a esta: 1) não se deve entender a linguagem como mera utilização de signos; 2) ela tampouco se liga à doação de sons e; 3) também não se dirige à consciência (KRÄMER, 2008). A síntese dessas três teses constitui um verdadeiro escândalo para toda filosofia da linguagem. Mais que isso, como assinala Kathrin Busch (2006), a proposta benjaminiana representa uma reverão da concepção tradicional das relações entre 0 homem e 0 mundo das coisas (Dingwelt). De componente ativo, o primeiro passa agora a elemento passivo, numa forma de relação onde cabe às coisas, o papel de agentes essenciais. As coisas se dirigem ao homem (em sua linguagem muda), para que este possa, então, nomeá-las. Se a lâmpada ou a montanha não se comunicassem ao homem, "como poderia ele nomeá-las? Mas ele as nomeia; ele se comunica ao nomeá-las" ${ }^{5}$ (BENJAMIN, 1991a, p. 143). ${ }^{6}$
A linguagem se liga, portanto, a um princípio de comunicabilidade (Mitteilbarkeit) geral; princípio extensivo a tudo que podemos experimentar. Todavia, o momento mais fascinante (e provavelmente também mais difícil) da argumentação encontra-se na distinção feita por Benjamin entre aquilo que se comunica

através da linguagem e o que se comunica na linguagem. 0 primeiro sentido é fácil de captar, já que corresponde à nossa concepção tradicional - burguesa, segundo Benjamin da linguagem. Nessa concepção, a linguagem aparece como mero veículo para a transmissão de informações externas a ela (uso a linguagem para falar do mundo, para descrever um jogo de futebol...). No segundo sentido, porém, revela-se algo inusitado. 0 que é aquilo que não é exterior e que não se comunica através da linguagem, mas antes, interiormente, nela mesma? Para complicar ainda um pouco mais, qual é a importância da distinção entre se comunicar (sich mitteilen) e comunicar algo (etwas mitteilen)? No primeiro caso, a linguagem deixa de ser entendida como meio (Mittel) para ser apreendida como meio (Medium). A repetição da palavra "meio" em português serve para apontar a dificuldade em traduzir as nuances semânticas dos dois diferentes termos em alemão. Pois, aqui, o primeiro termo tem 0 sentido que mais correntemente lhe atribuímos: um meio é um instrumento para a transmissão de algum conteúdo que lhe é exterior. A palavra "bola" é signo arbitrário que aponta para a ideia ou 0 objeto esférico material usado em jogos de futebol. Já o segundo, todavia, deve ser compreendido como um ambiente, um lócus (como, por exemplo,

\section{Er teilt sich mit, indem er sie bennent.}

Não se trata de preciosismo, mas de requisito indispensável fazer seguir certas traduções do texto das formulações originais. Dada a tremenda complexidade da argumentação e as sutilezas linguísticas a que as traduções por vezes têm que abdicar, a apresentação do termo alemão é fundamental para a compreensão dos argumentos - como se dá, por exemplo, na distinção entre Mittel e Medium, de que tratarei mais à frente. 
nas expressões "meio aquoso" ou "meio gasoso").

"Benjamin chama tal linguagem que transcende suas funções semióticas e instrumentais de ‘expressão' (Ausdruck)” (KRÄMER, 2008, p. 46). Entendida, portanto, como Medium, a linguagem constitui "expressão imediata daquilo que nela se comunica" (unmittelbare Ausdruck dessen, was sich in ihr mitteilt) (BENJAMIN, 1991, p. 141). Esse comunicar-se quer dizer, para Benjamin, mostrar-se:

\begin{abstract}
Nessa perspectiva, torna-se claro como Benjamin pode atribuir linguagem às coisas tanto quanto aos homens. Ambos podem expressar algo na medida em que mostram algo de si: a lâmpada se mostra ao emitir luz. Com isso, sugere-se que 'comunicar-se' significa um movimento o qual, em oposição a 'comunicar algo a alguém', é unidirecional, não visando, portanto, uma reciprocidade (KRÄMER, 2008, p. 46 , grifo da autora).
\end{abstract}

0 grande enigma agora, pois, é saber o que exatamente é aquilo que se comunica, que se mostra na linguagem e não através dela. Ora, o que a linguagem mostra enquanto Medium, o que ela comunica em si (sua "essência espiritual", para usar o místico termo benjaminiano $)^{7}$ é a "comunicabilidade" (Mitteilbarkeit). Ou seja, antes de dizer qualquer coisa externa a si mesma, a linguagem expressa imediatamente sua capacidade de comunicar. Nesse sufixo - barkeit, conforme mostrou brilhantemente Samuel Weber, esconde-se um princípio de virtualidade. A "comunic-abilidade" abarca o manancial inesgotável de potências daquilo que pode ser efetivamente comunicado. Referindose à discussão sobre os conceitos de meio $\mathrm{e}$ virtualidade, Weber passeia por Pierre Lévy, Deleuze e Hegel, mas começa seu percurso retornando a Aristóteles. Este último, em seu tratamento do problema da visão, pressupõe que, entre olho e objeto visto, deve haver algum meio (to metaxou), um entre-espaço ou in between, capaz de ligá-los. Esse meio não pode ser nem um intervalo passivo, nem uma realidade de ordem material. Só assim pode cumprir sua função de separação e ligação: "0 meio é aqui concebido como uma separação que todavia conecta, reúne, não diretamente, mas através de um movimento, de uma transmissão, de uma transformação" (WEBER, 2008, p. 34). Desse modo, todo fenômeno requer, de modo a ser percebido, um "medium" através do qual possa mover-se. Esta segunda ideia, de fato, é a mais interessante, já que a primeira simplesmente está na base de nossa noção tradicional do meio como algo transparente através do qual se manifesta aquilo que é realmente importante (o sentido, por exemplo). Todavia, tudo muda se a noção de meio passa a compreender não tanto um instrumento para se

Na excelente (e recentíssima) tradução de Susana Kampf Lages e Ernani Chaves, opta-se por verter "gesitiges Wesen" com a expressão mais neutra "conteúdo espiritual". Continuo preferindo, porém, o termo "essência espiritual", dado que aponta para as conexões da reflexão benjaminiana com o universo metafísico do romantismo alemão e da mística judaica, com o qual ele dialogou profundamente (BENJAMIN, 2011). 
apropriar do mundo, mas antes um movimento por meio do qual o mundo se constitui (WEBER, 2008, p. 36).

Para Weber, o sufixo - barkeit transforma os termos nos quais é aplicado, em algo inteiramente diferente do que eram em sua origem, e nesse tornar-se diferente (becomingdifferent), "a questão do meio, e da medialidade, começa a emergir" (WEBER, 2008, p. 40). Com esse sufixo, presente não somente no termo "comunicabilidade" (Mitteilbarkeit), mas também em outros como "traduzibilidade" (Übersetzbarkeit) ou "reprodutibilidade" (Reproduzierbarkeit), indica-se algo que é da ordem de uma virtualidade inesgotável. É por essa razão que Weber escolhe traduzir "Mitteilbarkeit" não como "communicability", mas antes através da palavra "impartability" (em português: "comunicar", "conceder", "conferir"). Para ele, "impartabilty" reproduz o movimento indicado pelo termo alemão "mitteilen" (partilhar-com): "o concedível (impartable) possui outro modo de ser [em relação ao atual], outra dinâmica, que consiste em sua transformação, seu tornarse outro. É a partir dessa tendência de ser alterado que emerge 0 'virtual'” (WEBER, 2008, p. 44). Na concepção benjaminiana, as coisas apelam ao homem, de modo que este possa nomeá-las. É assim que ele define sua "essência espiritual" como ser nomeador. Mas enquanto em Deus nome e conhecimento encontram-se em absoluta correspondência (Deus fala e as coisas se produzem), no homem nomear é sempre como que renomear: multiplicamos palavras, sobredeterminamos o mundo, traduzimos de uma língua para outra, pois no âmbito humano nunca existe totalidade, nunca se dá o encontro perfeito da coisa com o nome que lhe atribuímos. Daí a importância do permanente movimento de traduzibilidade entre as línguas - que indica a relação de incomensurabilidade entre 0 mundo humano e o mundo das coisas. E a partir disso, articula Weber (2008, p. 47, grifos nossos) uma das ideias mais importantes para estabelecer pontes entre Benjamin e Latour:

0 mundo, assim descrito, consiste não em
um simples e contínuo meio (medium), nem
mesmo em diferentes meios (media) que se
assemelham, mas antes em uma rede de
meios (network of media), cuja única particula-
ridade compartilhada é a habilidade de 'partir
com' no con-ceder (im-part).

Todas as coisas do mundo seriam, portanto, "meios" irredutíveis, singulares, cujo único dado em comum, entretanto, consistiria na possibilidade de "dividir-se e deslocar-se, de modo a entrar em contato 'com' outros” (WEBER, 2008, p. 45). Como rede na qual diversos atores (humanos e não humanos) estabelecem e desfazem vínculos entre si, esse mundo benjaminiano não estaria muito distante do cosmos de Latour. Segundo também assinala Krämer, o tema do "Medial", grande questão de fundo do pensamento de Benjamin, deve ser entendido no sentido de uma traduzibilidade geral. A potência "mágica" da linguagem (para empregar novamente um dos termos místicos do próprio 
Benjamin) consiste, em sua imediaticidade, na sua relação profunda com o problema da tradução. E é por essa razão que tal problema deve situar-se na camada mais profunda da teoria da linguagem, como noção fundadora e originária.

Quando Deus fala, Ele cria; quando o homem fala, traduz [...] A linguagem do homem não é um puro meio, (Medium), mas um híbrido de meio e instrumento: ela se tornou técnica, um órgão do conhecimento, e com isso de performatividade sempre fraturada (von nur noch gebrochener Performativität) (KRÄMER, 2008, p. 49).

Ora, essa perspectiva lembra decisivamente aquilo que Graham Harman (seguindo indicações do próprio Latour) definiu como o ponto de partida do pensamento latouriano (HARMAN; ERDÉLY; LATOUR, 2011). Para 0 autor de $A$ esperança de Pandora, o mundo é composto de entidades singulares e irredutíveis umas às outras (Benjamin diria: dotadas de "essência espiritual" específica). Todas têm igual estatuto ontológico e direito de cidadania; nenhuma delas pode ser reduzida a nenhuma outra. Podemos até elaborar teorias, emitir juízos sobre coisas e conjuntos de coisas, mas devemos sempre estar conscientes de que nada disso apreende ou totaliza realmente essas coisas de que falamos. Por outro lado, paradoxalmente, sempre é possível traduzir algo em termos de outra coisa - "contanto que façamos 0 trabalho de mostrar como uma pode ser transformada na outra, através de uma cadeia de consequências que sempre têm um preço e sempre se arrisca a fracasso" (HARMAN, 2009, p. 15). ${ }^{8}$ Nesse sentido, a verdade das coisas não consistiria na antiga definição filosófica da correspondência entre pensamento e realidade, mas sim numa série de traduções entre atores (HARMAN, 2009, p. 16). Discutindo o princípio de traduzibilidade em Benjamin, que naturalmente não se limita apenas à dimensão interlinguística, mas abarca também o processo de conversão da linguagem muda das coisas à língua sonora dos homens, Kathrin Busch (2006, p. 4) afirma:

Posição comparável defendeu mais recentemente Bruno Latour, que pretende compreender precisamente sob o conceito da tradução a transferência entre homem e coisas. Partindo da convicção de que a separação moderna entre sujeito e objeto é tão artificial quanto insustentável, ele argumenta que um sujeito intocado pelos objetos nunca existiu; antes, ambos formam associações simétricas no nível da ação [...] Como no caso de Benjamin, o status de objetos passivos já não é mais apropriado para as coisas: elas traduzem ações e assim possuem um papel formativo em sua determinação.

Na verdade, podemos ir um pouco mais longe e enxergar na obra de Benjamin a proposição de novas formas de subjetividade e história não mais centradas em preocupações especificamente humanas. Afinal, surpreende, no ensaio sobre A tarefa do tradutor, a afirmativa de que

Fracasso que, aliás, Benjamin assinalava como horizonte sempre possível de toda empresa tradutória - expresso já no ambíguo termo Aufgabe (simultaneamente interpretável como "tarefa" e "renúncia") no título de seu ensaio A tarefa do tradutor (die Aufgabe des Übersetzers). 
nenhuma obra de arte visa essencialmente seu receptor (BENJAMIN, 1991b, p. 9). Como se 0 campo dos objetos artísticos (e técnicos) fosse dotado de surpreendente autonomia, percebe-se uma corrosão do privilégio ontológico tradicionalmente atribuído à figura do humano. Para Beatrice Hanssen (1998, p. 1), o que se formula na obra benjaminiana é "o chamado ético-teológico por um outro tipo de história, não mais puramente antropocêntrica em sua natureza ou ancorada apenas nas preocupações dos sujeitos humanos". Desenha-se, assim, em Benjamin, um horizonte epistemológico onde 0 ser humano, tradicionalmente 0 senhor absoluto do conhecimento, se vê confrontado com pedras, anjos e animais. Emerge um bestiário de criaturas partilhando a terra de tal forma que o homem já não é mais claramente o pastor da criação.

É verdade que Latour manifesta uma preocupação - talvez não inteiramente demarcada em Benjamin - de estabelecer o elemento dissimétrico das relações entre os diversos atores (humanos e nãohumanos). Nitidamente, existem desigualdades e diferentes graus de influência. Todavia, trata-se de um universo plástico, dinâmico, no qual alianças e redes são criadas e desfeitas constantemente. Relações de força podem mudar - e isso efetivamente sucede com frequência. Como exemplifica humoristicamente Harman (2009, p. 21), "um pedregulho pode destruir um império se o Imperador engasgar-se durante o jantar". E é possível mesmo dizer que em muitas situações os atores não-humanos desempenham os papéis mais determinantes. Deve-se, ainda, destacar como significativa a ênfase com que Latour se preocupa em ressuscitar os objetos mortos para a sociologia tradicional. Um dos capítulos mais inspirados de Reassembling the Social é sua defesa da agência dos objetos ("Third Source of Uncertainty: Objects too Have Agency"). Para Latour (2005, p. 73), é difícil entender como mesmo após a Revolução Industrial eles possam ter continuado tão inócuos para o pensamento social ou a filosofia. Tudo se passa como se "uma maldição tivesse sido lançada sobre as coisas; elas permanecem adormecidas como os servos de algum castelo encantado".

Se adotamos uma perspectiva como a de Dorothee Kimmich, as posturas de Latour e Benjamin podem ser entendidas como reação ao projeto moderno (fracassado) de realizar nítidas separações entre os domínios da natureza e da cultura, do humano e do não-humano. ${ }^{9}$ De fato, a sensação da inquietante estranheza (Unheimliche) descrita por Freud (1976) evocada, por exemplo, a partir da incerteza sobre uma coisa ser animada ou inanimada, viva ou morta - se manifesta como um sintoma de que algo não funcionou bem nesse projeto de demarcação. Pois a literatura dos modernos tematizou constantemente a ultrapassagem de fronteiras entre o vivo e o não-vivo. E não se pode negar que o recente interesse pelas coisas parece 
indicar a ascensão de um "novo materialismo", um fascínio pelos objetos e pela materialidade do mundo. Como numa forma de reação ao longo domínio histórico dos valores espirituais, práticas interpretativas e pensamento antropocêntrico, estaríamos agora vivenciando uma nova forma de relação com as coisas. Para os modernos, esse contato foi frequentemente imaginado como traumático. Citando Latour, "filósofo do híbrido", e seu tratamento do tema do fetiche, explica Kimmich (2011, p. 23): "0 homem não é senhor em sua própria casa; mas ali não regem desejos inconscientes e sim as coisas. 0s homens se sentem não apenas excluídos do mundo das coisas, mas também ameaçados em seu próprio mundo".

Nesse sentido, é possível que Benjamin intuísse também que "jamais fomos modernos". E no autor de Infância berlinense - um livro onde os objetos possuem papel fundamental -, as coisas são de fato igualmente estranhas e familiares.

Elas devem ser encaradas com o olhar inocente da criança, para quem a separação radical entre 0 animado e 0 inanimado ainda não se deu.

Esse olhar infantil "marca uma interface entre técnica e esoterismo, que é típica do papel das coisas para Benjamin" (KIMMICH, 2011, p. 57). Trata-se do mesmo tipo de olhar exercido pelo colecionador, que se imagina na função de um messias resgatando os objetos de sua dispersão no mundo. Ambos se constituem como olhares antimodernos, ou seja, desprovidos das pretensões classificatórias e delimitadoras do projeto criticado por Latour.

\section{Conclusão}

Ainda se poderia dizer muito mais sobre afinidades que transcendem a possível conexão Benjamin-Latour, caracterizando-se como uma espécie de programa epistemológico que somente neste início de novo milênio assume feições mais claramente demarcáveis. Mas é tarefa que extrapola os limites do que se propõe neste artigo. A emergência de novas formas de materialismo (BENNET, 2010), a ascensão de uma filosofia orientada aos objetos (HARMAN, 2009), a configuração de um paradigma não-hermenêutico (GUMBRECHT, 2004), a reestruturação da noção de agência (LATOUR, 2005) apresentam-se a nós como uma única constelação a iluminar um firmamento comum. 0 que presenciamos é uma significativa transformação de paradigmas no horizonte das assim chamadas "Ciências Humanas" (mas cuja própria designação já foi também problematizada por tal transformação). Como se trata de cenário ainda novo - mas cuja genealogia pode ser traçada na contribuição de precursores como Benjamin, McLuhan e Heidegger, por exemplo -, seguimos aguardando o surgimento de cartografias mais precisas dos territórios que se descortinam à nossa frente.

No que se refere às ciências da comunicação, parece-me claro que as transformações em curso exigirão a revisão ampla de metodologias, conceitos e paradigmas (especialmente das noções de "meio" e "comunicação"). Não se 
trata, obviamente, de simplesmente abandonar antigos modelos e programas de pesquisa, mas sim de repensá-los face aos novos problemas e indagações, bem como desenvolver novas formas de abordagem. A dominância de perspectivas semióticas na comunicação deve, no mínimo, ser contrabalançada por esforços para empreender uma ocasional "abstinência hermenêutica" (KIMMICH, 2011, p. 20). Pois é tentando deixar que as coisas falem por si mesmas (em vez de constantemente atribuirlhes sentido) que nos engajaremos na tentativa de desenvolver esse outro olhar - da criança, do colecionador, do homem maravilhado.

Precisaremos de outras categorias para descrever esse jovem e perturbador mundo dos objetos. Mais que tudo, é necessário superar a ilusão da transparência tecnológica - bastante resistente em sua associação a noções como "meios" e "mediações", frequentemente usados como termos autoevidentes. Nesse cenário, mesmo as antigas certezas merecem uma ponta de desconfiança. 0 que deve significar, por exemplo, o termo "comunicação" após sua reestruturação no âmbito da teoria de sistemas de segunda ordem de Niklas Luhmann? ${ }^{10}$ Evidentemente, muitos pesquisadores podem simplesmente escolher ficar alheios a essa avalanche de reformas que se anuncia. A academia não é imune a uma razoável dose de autismo. As "caixas pretas" das teorias estabelecidas oferecem, evidentemente, resistência a sua desconstrução. Todavia, como
Latour ensina, não há mais caixas pretas que não possam ser abertas.

\section{Referências}

BENJAMIN, Walter. Aufsätze, Essays, Vorträge

(Gesammelte Schriften, Band II-1). Frankfurt:

Suhrkamp, 1991a.

. Kleine Prosa: Baudelaire Übertragungen

(Gesammelte Schriften Band IV-1). Frankfurt: Suhrkamp, 1991b.

Escritos sobre mito e linguagem. Trad. de Susana Kampf Lages e Ernani Chaves. Rio de Janeiro: Editora 34, 2011.

BENNET, Jane. Vibrant Matter: a Political Ecology of Things. Durham: Duke University Press, 2010.

BERMAN, Antoine. LẦge de la Traduction - "La Tâche du Traducteur" de Walter Benjamin: un Commentaire. Paris: Presses Universitaires de Vincennes, 2008.

BLO0M, Harold. The Anxiety of Influence: a Theory of Poetry. New York: Oxford University Press, 1997. BUSCH, Kathrin. Dingsprache und Sprachmagie: Zur Idee latenter Wirksamkeit bei Walter Benjamin. eipcp multilingual webjournal. Dic. 2006. Disponível em $<$ http://eipcp.net/transversal/0107/busch/de > Acesso em: 10 mar. 2008.

FELINTO, Erick. Vampyroteuthis: a Segunda Natureza do Cinema. A 'Matéria' do Filme e o Corpo do Espectador. Flusser Studies, n. 10, nov. 2010. Disponível em < http:// www.flusserstudies.net/pag/10/felinto-vampyroteuthis. pdf > . Acesso em: 15 mar. 2013.

FREUD, Sigmund. Obras Psicológicas Completas - Edição Standard (Vol. XVII - 1917-1919). Rio de Janeiro: Imago, 1976. 
GUMBRECHT, Hans Ulrich. The Production of Presence: What Meaning Cannot Convey. Stanford: Stanford University Press, 2004.

HANSEN, Mark. New Philosophy for New Media.

Cambridge: the MIT Press, 2004.

HANSSEN, Beatrice. Walter Benjamin's Other

History: of Stones, Animals, Human Beings and Angels. Berkeley: University of California Press, 1998.

HARMAN, Graham. Prince of Networks: Bruno Latour and Metaphysics. Melbourne: Re.Press, 2009.

KIMMICH, Dorothee. Lebendige Dinge in der

Moderne. Padeborn: Konstanz University Press, 2011.

KRÄMER, Sybille. Medium, Bote, Übertragung: kleine Metaphysik der Medialität. Suhrkamp, 2008.

LATOUR, Bruno. Reassembling the Social: an Introduction to Actor-Network Theory. Oxford: Oxford University Press, 2005.

HARMAN, Graham; ERDÉLY, Peter. The

Prince and the Wolf: Latour and Harman at the LSE. Winchester: Zero Books, 2011.

Pandora's Hope: Essays on the Reality

of Science Studies. Cambridge: Harvard University

Press, 2000.

Jamais fomos modernos: ensaio de

antropologia simétrica. Rio de Janeiro: Editora 34, 1994.

; HENNION, Antoine. How to make mistakes on so many things at once - and become famous for it. In: GUMBRECHT, Hans Ulrich; MARRINAN, Michael (Org.). Mapping Benjamin: The Work of Art in the Digital Age. Stanford: Stanford University Press, 2003.

LUHMANN, Niklas. A improbabilidade da comunicação. Lisboa: Vega, 2006.

Was ist Kommunikation? In: SIMON, F. B.

Lebende Systeme. Wirklichkeitskonstruktionen in der systemischen Therapie. Berlin: Springer, 1998.
MENNINGHAUS, Winfried. Walter Benjamins Theorie der Sprachmagie. Frankfurt: Suhrkamp, 1995.

MARRIMAN, Michael; GUMBRECHT, Hans Ulrich.

Mapping Benjamin: the work of art in the digital age.

Stanford: Stanford University Press, 2003.

MOELLER, Hans-Georg. Luhmann Explained: From

Souls to Systems. Chicago: Open Court, 2006.

MORONCINI, Bruno. Walter Benjamin e la Moralità del Moderno. Napoli: Guida, 1984.

SCHÖTTKER, Detlev. Kommentar. In: BENJAMIN, Walter. Das Kunstwerk im Zeitalter seiner technischen Reproduzierbarkeit. Frankfurt: Suhrkamp, 2007.

WEBER, Samuel. Benjamin's -Abilities. Cambridge: Harvard University Press, 2008.

WIGGERSHAUS, Rold. The Frankfurt School: Its History, Theories and Political Significance. Cambridge: The MIT Press, 1995. 
Medium, Mediation, Agency: the Discovery of Objects in Walter Benjamin and Bruno Latour

\section{Abstract}

Notwithstanding the originality of Bruno Latour's propositions, it would be a mistake to assume that his work emerged in a theoretical vacuum. For instance, critics have meticulously examined the influence of thinkers such as Étienne Souriau, Gilbert Simondon and Gabriel Tarde on Latour's arguments. The goal of this paper is to sketch some important similarities between Latour's thought and certain ideas developed by Walter Benjamin (specially in his early writings). This rapprochement between Latour and Benjamin, already hinted at by some authors, enables us to endeavor a philosophical exploration of the concepts of agency, medium and mediation, which are fundamental for media theory, especially within the context of contemporary culture.

\section{Keywords}

Bruno Latour. Walter Benjamin. Agency.

Mediation. Communication.
Médium, Mediación, Agencia: la Descubierta de los Objetos en Walter Benjamin y Bruno Latour

\section{Resumen}

No obstante la originalidad de las proposiciones de Bruno Latour, sería un error creer que su obra surgió a partir de un vacío teórico. Por ejemplo, los críticos han examinado cuidadosamente la influencia de pensadores como Étienne Souriau, Gilbert Simondon y Gabriel Tarde. El objetivo de este trabajo es bosquejar alguns importantes similitudes entre el pensamiento de Latour y ciertas ideas desarrolladas por Walter Benjamin (especialmente en sus escritos de juventud). Ese acercamiento entre Latour y Benjamin, ya indicado por algunos autores, permite emprender una exploración filosófica de los conceptos de agencia, médium y mediación, que son fundamentales para la teoría de los medíos, especialmente en el contexto contemporáneo.

\section{Palabras-Clave}

Bruno Latour. Walter Benjamin. Agencia.

Mediación. Comunicación. 


\section{Expediente}

A revista E-Compós é a publicação científica em formato eletrônico da Associação Nacional dos Programas de Pós-Graduação em Comunicação (Compós). Lançada em 2004, tem como principal finalidade difundir a produção acadêmica de pesquisadores da área de Comunicação, inseridos em instituições do Brasil e do exterior.
E-COMPÓS I www.e-compos.org.br I E-ISSN 1808-2599

Revista da Associação Nacional dos Programas

de Pós-Graduação em Comunicação.

E-compós, Brasilia, v.16, n.1, jan./abr. 2013

A identificação das edições, a partir de 2008,

passa a ser volume anual com três números.

\section{CONSELHO EDITORIAL}

Afonso Albuquerque, Universidade Federal Fluminense, Brasil Alberto Carlos Augusto Klein, Universidade Estadual de Londrina, Brasil Álvaro Larangeira, Universidade Tuiuti do Paraná, Brasil André Luiz Martins Lemos, Universidade Federal da Bahia, Brasil Ângela Freire Prysthon, Universidade Federal de Pernambuco, Brasil Angela Cristina Salgueiro Marques, Faculdade Cásper Líbero (São Paulo), Brasil Antonio Roberto Chiachiri Filho, Faculdade Cásper Líbero, Brasil Arthur Autran Franco de Sá Neto, Universidade Federal de São Carlos, Brasil Benjamim Picado, Universidade Federal Fluminense, Brasil César Geraldo Guimarães, Universidade Federal de Minas Gerais, Brasil Cristiane Freitas Gutfreind, Pontifícia Universidade Católica do Rio Grande do Sul, Brasil

Denilson Lopes, Universidade Federal do Rio de Janeiro, Brasil Eduardo Peñuela Cañizal, Universidade Paulista, Brasil

Eduardo Vicente, Universidade de São Paulo, Brasil Eneus Trindade, Universidade de São Paulo, Brasil Erick Felinto de Oliveira, Universidade do Estado do Rio de Janeiro, Brasil Florence Dravet, Universidade Católica de Brasília, Brasil Gelson Santana, Universidade Anhembi/Morumbi, Brasil Gislene da Silva, Universidade Federal de Santa Catarina, Brasil Guillermo Orozco Gómez, Universidad de Guadalajara Gustavo Daudt Fischer, Universidade do Vale do Rio dos Sinos, Brasil Hector Ospina, Universidad de Manizales, Colômbia Herom Vargas, Universidade Municipal de São Caetano do Sul, Brasil Inês Vitorino, Universidade Federal do Ceará, Brasil Jay David Bolter, Georgia Institute of Technology Jeder Silveira Janotti Junior, Universidade Federal de Pernambuco, Brasil John DH Downing, University of Texas at Austin, Estados Unidos José Afonso da Silva Junior, Universidade Federal de Pernambuco, Brasil José Carlos Rodrigues, Pontifícia Universidade Católica do Rio de Janeiro, Brasil José Luiz Aidar Prado, Pontifícia Universidade Católica de São Paulo, Brasil Kelly Cristina de Souza Prudêncio, Universidade Federal do Paraná, Brasil.
Laan Mendes Barros, Universidade Metodista de São Paulo, Brasil Lance Strate, Fordham University, USA, Estados Unidos Lorraine Leu, University of Bristol, Grã-Bretanha Lucia Leão, Pontifícia Universidade Católica de São Paulo, Brasil Malena Segura Contrera, Universidade Paulista, Brasil

Márcio de Vasconcellos Serelle, Pontifícia Universidade Católica de Minas Gerais, Brasil

Maria Aparecida Baccega, Universidade de São Paulo e Escola Superior de Propaganda e Marketing, Brasil

Maria Ataide Malcher, Universidade Federal do Pará, Brasil

Maria das Graças Pinto Coelho, Universidade Federal do Rio Grande do Norte, Brasil Maria Immacolata Vassallo de Lopes, Universidade de São Paulo, Brasil Maria Luiza Martins de Mendonça, Universidade Federal de Goiás, Brasil Mauro de Souza Ventura, Universidade Estadual Paulista, Brasil Mauro Pereira Porto, Tulane University, Estados Unidos Mirna Feitoza Pereira, Universidade Federal do Amazonas, Brasil Nilda Aparecida Jacks, Universidade Federal do Rio Grande do Sul, Brasil Osvando J. de Morais, Universidade de Sorocaba, Brasil Potiguara Mendes Silveira Jr, Universidade Federal de Juiz de Fora, Brasil Renato Cordeiro Gomes, Pontifícia Universidade Católica do Rio de Janeiro, Brasil Robert K Logan, University of Toronto, Canadá

Ronaldo George Helal, Universidade do Estado do Rio de Janeiro, Brasil Rose Melo Rocha, Escola Superior de Propaganda e Marketing, Brasil Rossana Reguillo, Instituto de Estudos Superiores do Ocidente, Mexico Rousiley Celi Moreira Maia, Universidade Federal de Minas Gerais, Brasil Sebastião Guilherme Albano da Costa, Universidade Federal do Rio Grande do Norte, Brasil

Simone Maria Andrade Pereira de Sá, Universidade Federal Fluminense, Brasil Tiago Quiroga Fausto Neto, Universidade de Brasília, Brasil Suzete Venturelli, Universidade de Brasília, Brasil Valerio Fuenzalida Fernández, Puc-Chile, Chile

Veneza Mayora Ronsini, Universidade Federal de Santa Maria, Brasil Vera Regina Veiga França, Universidade Federal de Minas Gerais, Brasil

\section{COMISSÃO EDITORIAL}

Adriana Braga I Pontifícia Universidade Católica do Rio de Janeiro, Brasil

Felipe Costa Trotta I Universidade Federal Fluminense, Brasil

CONSULTORES AD HOC

Bruno Campanella, Universidade Federal Fluminense, Brasil

Christa Berger, Universidade do Vale do Rio dos Sinos, Brasil

Edison Gastaldo, Universidade Federal Rural do Rio de Janeiro, Brasil

José Luiz Braga, Universidade do Vale do Rio dos Sinos, Brasil

\section{EDIÇÃO DE TEXTO E RESUMOS I Susane Barros}

SECRETÁRIA EXECUTIVA I Juliana Depiné

EDITORACã̃ ELETRÔNICA I Roka Estúdio
COMPóS I www.compos.org.br

Associação Nacional dos Programas de Pós-Graduação em Comunicação

Presidente

Julio Pinto

Pontifícia Universidade Católica de Minas Gerais, Brasil juliopinto@pucminas.br

Vice-presidente

Itania Maria Mota Gomes

Universidade Federal da Bahia, Brasil

itania@ufba.br

Secretária-Geral

Inês Vitorino

Universidade Federal do Ceará, Brasil

inesvic@gmail.com 